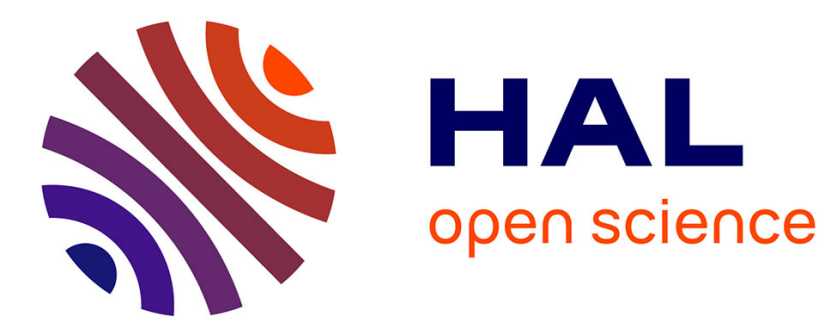

\title{
Role of coagulase-negative staphylococci in human disease
}

\author{
A. Piette, G. Verschraegen
}

\section{To cite this version:}

A. Piette, G. Verschraegen. Role of coagulase-negative staphylococci in human disease. Veterinary Microbiology, 2009, 134 (1-2), pp.45. 10.1016/j.vetmic.2008.09.009 . hal-00532477

\section{HAL Id: hal-00532477 \\ https://hal.science/hal-00532477}

Submitted on 4 Nov 2010

HAL is a multi-disciplinary open access archive for the deposit and dissemination of scientific research documents, whether they are published or not. The documents may come from teaching and research institutions in France or abroad, or from public or private research centers.
L'archive ouverte pluridisciplinaire HAL, est destinée au dépôt et à la diffusion de documents scientifiques de niveau recherche, publiés ou non, émanant des établissements d'enseignement et de recherche français ou étrangers, des laboratoires publics ou privés. 


\section{Accepted Manuscript}

Title: Role of coagulase-negative staphylococci in human disease

Authors: A. Piette, G. Verschraegen

PII: $\quad$ S0378-1135(08)00363-5

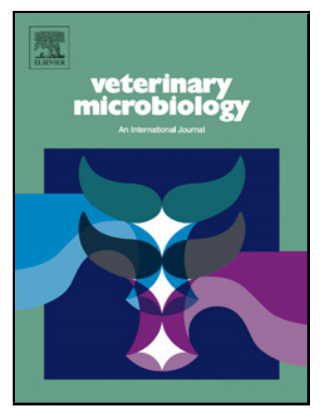

DOI: $\quad$ doi:10.1016/j.vetmic.2008.09.009

Reference: $\quad$ VETMIC 4148

To appear in: $\quad$ VETMIC

Please cite this article as: Piette, A., Verschraegen, G., Role of coagulasenegative staphylococci in human disease, Veterinary Microbiology (2008), doi:10.1016/j.vetmic.2008.09.009

This is a PDF file of an unedited manuscript that has been accepted for publication. As a service to our customers we are providing this early version of the manuscript. The manuscript will undergo copyediting, typesetting, and review of the resulting proof before it is published in its final form. Please note that during the production process errors may be discovered which could affect the content, and all legal disclaimers that apply to the journal pertain. 
Role of coagulase-negative staphylococci in human disease.

A. Piette*, G. Verschraegen

Department of Microbiology, University Hospital Ghent, Belgium

4

De Pintelaan 185, 9000 Gent

5

6

* Corresponding author. Tel.: +32 9 3326639; Fax: +32 93324985

7

E-mail address: anne.piette@ugent.be

8

9 

1

\section{Abstract}

Coagulase-negative staphylococci (CNS) are normal inhabitants of human skin and mucous membranes. They have long been dismissed as culture contaminants, but now the potentially important role of CNS as pathogens and their increasing incidence has been recognized.

Approximately $55 \%-75 \%$ of nosocomial isolates is methicillin resistant. CNS were the first organisms in which glycopeptide resistance was recognized. In the immunocompetent host, CNS endocarditis and urinary tract infections with Staphylococcus saprophyticus are the most common CNS infections. Other patients are usually immunocompromised, with indwelling or implanted foreign bodies. CNS account for approximately $30 \%$ of all nosocomial blood stream infections. The majority of these concern catheter-related sepsis. Other important infections due to CNS include central nervous system shunt infections, endophthalmitis, surgical site infections, peritonitis in patients with continuous ambulatory peritoneal dialysis and foreign body infections. CNS are rarely associated with mastitis in humans. Staphylococcus lugdunensis is more pathogenic than other CNS as it expresses several potential virulence factors. The distinction between clinically significant, 4 pathogenic and contaminating isolates is a major problem. Several studies show clonal intra and inter hospital spread of Staphylococcus epidermidis strains which suggests that infection control measures may be necessary for multiresistant CNS isolates as for methicillin resistant Staphylococcus aureus. 7 As a result of medical progress, mainly due to the use of invasive and indwelling medical devices, 8 CNS are now a major cause of nosocomial and health-care related infections.

29 Keywords: coagulase-negative staphylococci, human medicine, species distribution, antibiotic 30 resistance, endocarditis, urinary tract infections, blood stream infections, nosocomial infection 


\section{Introduction}

Coagulase-negative staphylococci (CNS) are normal inhabitants of human skin and mucous membranes. They were first described in 1884 by Rodenbach as Staphylococcus albus, an avirulent staphylococcus. They have long been dismissed as culture contaminants, even in type 1 samples (samples obtained from a normally sterile site by needle aspiration or surgery). Only in 1958 the first report on the potential pathogenicity of CNS in patients with septicaemia was published (Smith et al., 1958). Later on, casuistic reports of CNS endocarditis, wound and urinary tract infections (UTI) appeared (Kloos et al., 1994). Since the 1970s, CNS are recognised as etiologic agents of a wide variety of infections. Patients with CNS infections are usually immunocompromised, with indwelling or implanted foreign bodies. CNS play a role in bacteraemia, central nervous system shunt infection, endocarditis, urinary tract infection, surgical site infections, endophthalmitis, foreign body infection and many other infections. The distinction between clinically significant, pathogenic and contaminating isolates is difficult and remains a major problem.

An overview of the medical literature on CNS is given, with special focus on identification, species distribution, virulence factors, antibiotic resistance, epidemiology and specific infections caused by CNS in humans.

\section{Identification}

Before 1975, S. albus or S. epidermidis was distinguished from S. aureus by the inability to clot blood plasma. Today, tests based on coagulase production and the thermonuclease reaction are used for rapid differentiation of S. aureus from other staphylococcal species (Huebner et al., 1999).

Currently, 39 species of CNS are recognized (Euzéby, 2007). Sixteen of these species have been

5 found in specimens of human origin. They are grouped in novobiocin-resistant species (S. cohnii, S. saprophyticus, S. sciuri, S. xylosis) and novobiocin-susceptible species (S. auricularis, S. capitis, $S$. 
caprae, S. epidermidis, S. haemolyticus, S. hominis, S. lugdunensis, S. pasteuri, S. saccharolyticus, $S$. schleiferi, S. simulans, S. warneri) (von Eiff et al., 2001).

Accurate identification of CNS isolates to species level is difficult to perform and expensive. According to Huebner et al., 1999, identification to species level is, in general, not necessary for good patient management. However, recent literature indicates accurate species identification is necessary to provide a better understanding of pathogenic potential of various CNS species (Heikens et al., 2005; Sivadon et al., 2005).

Before 1975, CNS were classified in different biotypes, according to Baird-Parker. In 1975, Kloos and Schleifer proposed a scheme for identification of staphylococci in the routine laboratory. This scheme is based on 13 key characteristics, such as coagulase activity, hemolysis, nitrate reduction and aerobic acid production from carbohydrates (Kloos et al., 1975). Nowadays, besides phenotypic methods, a variety of genotypic methods (16S rRNA, sodA, gap, rpoB, tuf gene sequencing) have been developed (Heikens et al., 2005; Layer et al., 2006; Mellmann et al., 2006). Heikens et al. compared phenotypic with genotypic (16S rRNA gene and tuf gene sequencing) identification (Heikens et al., 2005). The results showed that tuf gene sequencing is the best identification method ( 5 of 57 isolates misidentified). The API staph ID test (BioMérieux, Marcy l'Etoile, France) appeared to be a reliable alternative ( 7 of 57 isolates misidentified). The performance of the BD Phoenix system (Becton Dickinson Diagnostic Systems, Sparks, MD, USA) was poor. A recent study (Layer et al., 2006) compared 3 phenotypic, commercial identification methods with a molecular identification method (gap based terminal restriction fragment length polymorphism analysis) as reference method. The BD Phoenix ID-13 system (Becton Dickinson Diagnostic Systems) identified 18 of 27 reference strains and 70 of 86 clinical isolates correctly, the VITEK 2 ID-GP system (BioMérieux) 20 of 27 reference strains and 80 of 86 clinical isolates, the ID 32 STAPH system (BioMérieux) 23 of 27 reference strains and 19 of 20 clinical isolates. Thus, genotypic methods are superior to phenotypic methods, but some phenotypic methods have a highly 

acceptable level of identification accuracy when used in routine practice (Heikens et al., 2005; Layer et al., 2006).

\section{Species distribution}

Interpretation and comparison of the species distribution found in different studies is very difficult. The type of identification method used, may influence the species distribution found and some Staphylococcus species demonstrate habitat or niche preference. S. capitis for example is mainly found on the adult head, $S$. cohnii on the feet. S. saprophyticus is found in urine of young women (Kloos et al., 1994; Bannerman, 2003).

S. epidermidis, S. haemolyticus and S. hominis are the most frequently encountered CNS species in clinical samples. The isolation frequency of the different CNS species in clinical, human specimens is shown in Table 1 . Usually, more than $50 \%$ of CNS isolates belong to the species $S$. epidermidis. In India, low percentages of S. epidermidis were found (13.2\%) and high percentages of S. haemolyticus (71.9\%) (Chaudhury et al., 2007). A Japanese study (Kawamura et al., 1998) found a very high percentage of $S$. caprae $(14 \%)$, while the frequency of isolation in other studies is very low. In the study by Kawamura et al., 1998, all isolates were identified by a DNA-DNA hybridisation and by conventional, phenotypic identification based on the Kloos and Schleifer method. None of the S. caprae isolates was identified correctly by the phenotypic method.

In Spanish point prevalence studies in a large group of hospitals, performed from 1986 to 2002, showed no major shifts in the distribution of CNS species (Cuevas et al., 2004). When the distribution in 2002 is compared with 1986, there is a decrease in isolation of S. epidermidis, $S$. simulans, S. cohnii and S. xylosis and an increase in isolation of S. hominis and S. saprophyticus.

S. epidermidis is the predominant pathogen in intravascular catheter-related infections, nosocomial bacteremia, endocarditis, urinary tract and surgical wounds infections, central nervous system shunt infections, ophthalmologic infections, peritoneal dialysis-related infections and infections of 
108 prosthetic joints (Bannerman, 2003). S. haemolyticus has been implicated in native valve

109 endocarditis, septicemia, urinary tract infections, peritonitis and wound, bone and joint infections

110 (Bannerman, 2003). S. saprophyticus is associated with urinary tract infections in young females. $S$.

111 lugdunensis has been implicated in arthritis, catheter infections, bacteremia, urinary tract infections,

112 prosthetic joint infections and endocarditis (Bannerman, 2003). Other CNS species have been

113 implicated in a variety of infections.

4. Virulence factors

Already in 1972, the "slime" production of CNS was noted as an important factor in the pathogenesis of infections (Huebner et al., 1999). This "slime" or biofilm is the most important virulence factor of $S$. epidermidis. The biofilm formation enables attachment and persistence of the bacteria on foreign materials. Moreover, bacteria organized in biofilms are protected from the action of antibiotics and the immune system (Costerton et al., 1999; Mack et al., 2007). The first phase in biofilm formation is attachment, in which staphylococcal binding proteins such as the autolysin/adhesins AtlE and Aae, the fibrinogen-binding protein Fbe/Sdrg, the fibronectin-binding protein Embp and the lipase GehD, play an important role (Mack et al., 2007). The most important adhesion molecule is AtlE. The second phase in biofilm formation is accumulation, in which the polysaccharide intercellular protein PIA, encoded by the icaADBC locus, is a major functional component (von Eiff et al., 2002; Mack et al., 2007). In strains lacking the icaADBC locus, biofilm formation is mediated by the accumulation-associated protein (Aap) or by the biofilm-associated protein (Bap/Bhp) (Ziebuhr et al., 2006). Recently, 2 biofilm producing strains, negative for PIA, 130 Aap and Bhp, have been described (Qin et al., 2007). The regulation of biofilm formation is very 131 complicated and best studied in S. epidermidis. Different regulatory systems, such as sae, alternative

132 sigma factor $\sigma^{\mathrm{B}}$, sar and quorum sensing (this is inter and intra species communication, possible 133 when a certain bacterial density has been established) systems play a role (Xu et al., 2006; Mack et 
134 al., 2007). The 2 quorum sensing systems in S. epidermidis, agr and luxS/AI-2, repress the biofilm

135 formation: luxS system by downregulating PIA production, agr system by downregulating AtlE 136 production. $A g r$ controls the expression of toxins and secreted virulence factors and the interaction 137 with the immune system (Kong et al., 2006). Quorum sensing systems have potential as therapeutic 138 targets for control of staphylococcal infections (Harraghy et al., 2007). Another important virulence 139 factor of CNS is the antibiotic resistance. Regulation of biofilm formation and methicillin resistance 140 seem to use similar pathways, as insertion of a certain transposon influences both biofilm formation 141 and the expression of methicillin resistance (Mack et al., 2007). Methicillin resistance was found to 142 be significantly higher in slime positive isolates (81\%) than in slime negative isolates (57\%) (Koksal 143 et al., 2007).

The phenotypic variability and heterogeneous gene expression observed in CNS, especially in S. epidermidis, is an advantage for adaptation to changing environmental conditions (Ziebuhr et al., 2006).

Other potential virulence factors of $S$. epidermidis include the following: extracellular

148 enzymes and toxins: metalloprotease with elastase activity, cysteine protease, serine protease, lipase,

149 fatty acid modifying enzymes (FAME) and the $\delta$-toxin. CNS also produce lantibiotics (von Eiff et 150 al., 2002; Vuong et al., 2002). Lantibiotics are bacteriocins such as epidermin, which are active 151 against other gram-positive bacteria.

Several studies tried to discriminate between invasive and commensal S. epidermidis strains

153 by the detection of virulence associated genes (Frebourg et al., 2000; Vandecasteele et al., 2003;

154 Rohde et al., 2004). In the study by Rohde et al (Rohde al., 2004) the virulence genes icaADBC, mecA and IS256 were all highly prevalent in invasive strains. Commensal strains from healthy 156 individuals almost completely lacked icaADBC, mecA and IS256. However in the commensal 157 strains isolated from hospitalized bone marrow transplant patients the studied genes had the same 158 distribution as the invasive strains, suggesting replacement of their own commensal flora by hospital 159 strains. As a consequence these genes cannot discriminate between invasive and commensal strains. 
161 they may express a clumping factor and/or produce a thermostable DNAse (von Eiff et al., 2002). A

162 variable percentage of these strains produces extracellular slime or glycocalix, esterase, FAME,

163 protease, lipase and a haemolysin. S. lugdunensis is more likely than other CNS, to be considered a

164 pathogen until proven otherwise (Poutanen et al., 2001; Koziol-Montewka et al., 2006). S.

165 lugdunensis is often misidentified as $S$. aureus, because slide agglutination tests are often positive.

166 The main virulence factor of S. saprophyticus in UTI is the capacity to adhere to uroepithelial

167 cells by means of surface-associated proteins: the autolysin/adhesin Aas, Ssp and Sdrl. Once

168 colonization has been established several invasion factors are produced: urease, elastase, lipase and

169 FAME (von Eiff et al., 2002).

\section{5. Antibiotic resistance}

Resistance to antibiotics in CNS is of major concern. Penicillin resistance in CNS is very

174 high: even in 1968 the resistance rate was 60\% (Corse et al., 1968). Nowadays, resistance is around

$17591 \%$ in clinical strains (Cuevas et al., 2004; Koksal et al., 2007). Methicillin resistance in

176 staphylococci is caused by expression of PBP2a encoded by the mecA gene. MecA is located on a

177 genetic element called the staphylococcal cassette chromosome (SCC). There is evidence of

178 horizontal transfer of SCC cassettes between staphylococcal species (Hanssen et al., 2004), which

179 implies that CNS could serve as a reservoir for the spread of resistance genes to $S$. aureus. In clinical

180 samples, rates of methicillin resistance of $55 \%-77 \%$ and even $86 \%$ in ICU settings, have been

181 reported (Del' Alamo et al., 1999; Agvald-Öhman et al., 2004; Cuevas et al., 2004; Chaudhury et al.,

182 2007; Gatermann et al., 2007; Jones et al., 2007a; Jones et al., 2007b; Koksal et al., 2007; Sader et

183 al., 2007;). In continuous ambulatory peritoneal dialysis (CAPD) patients and medical students 38\%

184 and 27\%, respectively, of colonizing CNS strains were methicillin resistant (de Mattos et al., 2003;

185 Koziol-Montewka et al., 2006; Higuchi et al., 2007). Several studies show an increase of MR CNS 
over time. In Spain, methicillin or oxacillin resistance remained stable (26\%-34\% of CNS) between 1986 and 1994, increased significantly in 1996 (51\%) and reached 61\% in 2002 (Cuevas et al., 2004). An increase of methicillin resistant CNS strains was also found in other studies: from $38 \%$ in 1996 to $68 \%$ in 2007 in blood of patients with true bacteremia (Koksal et al., 2007), from 19\% in 1991 to $74 \%$ in 1998 in peritoneal dialysis patients (Zelenitsky et al., 2000). It is generally assumed that approximately $80 \%$ of nosocomial isolates and $30-40 \%$ of isolates obtained from healthy carriers or patients from the community, demonstrate resistance to methicillin (Huebner et al., 1999; de Mattos et al., 2003; Koziol-Montewka et al., 2006).

In Spain, resistance to ciprofloxacin and erythromycin increased progressively in CNS from $1 \%$ and $41 \%$ in 1986 to $45 \%$ and $63 \%$ in 2002 (Cuevas et al., 2004). Susceptibility percentages to different antibiotics are given in Table 2. Two surveillance studies, performed in 2006, one in the US and one in Europe, Asia, Australia and Latin America show comparable susceptibility results. Susceptibility rates to fluoroquinolones, erythromycin, clindamycin, trimethoprim/sulfamethoxazole, gentamicin, teicoplanin and linezolid are 42\%-47\%, 30\%-34\%, 60\%-61\%, 62\%-59\%, 71\%-58\%, 99 and 98-99\%, respectively (Jones et al., 2007a, Jones et al., 2007b). Methicillin resistant strains have high rates of resistance to other classes of antibiotics. Resistance rates in methicillin susceptible strains are much lower (Reynolds et al., 2004; Biedenbach et al., 2007; Koksal et al., 2007; Sader et al., 2007).

CNS were the first organisms in which acquired glycopeptide resistance (vancomycin MIC $\geq 8 \mu \mathrm{g} / \mathrm{mL}$, teicoplanin MIC $\geq 16 \mu \mathrm{g} / \mathrm{mL}$ ) was recognized (Biavasco et al., 2000). Most of the clinical glycopeptides resistant isolates are resistant to teicoplanin, but susceptible to vancomycin, indicating a heterogeneous expression of glycopeptides resistance (Nunes et al., 2006). The resistance mechanisms to glycopeptides in CNS are not yet fully understood. Most reports show that resistance mechanism in CNS is similar to that described in VISA and hetero-VISA strains (Nunes et al., 2006). This mechanism is multifactorial, expression related and can be selected, in vitro, by exposure to teicoplanin and vancomycin (Biavasco et al., 2000; Nunes et al., 2006). Laboratory detection of 
212 glycopeptide-resistance may be problematic, as there is an influence of various technical factors.

213 Susceptibility testing by disk diffusion results in a very high percentage of false susceptible results 214 (very major errors in $80 \%$ of the nonsusceptible to teicoplanin strains) (Del' Alamo et al., 1999). 215 Susceptibility rates to vancomycin and teicoplanin of respectively $99 \%-100 \%$ and $68 \%-100 \%$ are 216 found in clinical studies (Del' Alamo et al., 1999; Cuevas et al., 2004; Reynolds et al., 2004; 217 Chaudhury et al., 2007; Koksal et al., 2007; Sader et al., 2007).

Novel antibiotics have been developed to overcome the resistance problem in CNS. These antibiotics include for example linezolid, daptomycin, tigecycline and quinupristin/dalfopristin. Susceptibility of CNS isolates towards these agents is usually 100\% (Garrison et al., 2005; Sader et al., 2007). In recent surveillance studies the lowest reported susceptibility percentages are $98,4 \%$ for linezolid (Jones et al., 2007a), 99\% for quinupristin/dalfopristin (Jones et al., 2007b) and 99,9\% for daptomycin (Sader et al., 2007). In one institution, 4\% of CNS, originating from 25 patients, were found to be linezolid resistant. The majority of these resistant strains showed some genetic relatedness, previous linezolid use was an independent predictor of linezolid resistance and the majority of patients had been accommodated in a single ward (Potoski et al., 2006). of resistance are found in S. haemolyticus: 76-96\% oxacillin resistant, 80-90\% erythromycin resistant, 26-29\% teicoplanin nonsusceptible (Gill et al., 1983; Del' Alamo et al., 1999; Chaudhury et al., 2007; Gatermann et al., 2007). Oxacillin resistance rates are also high in S. hominis (80\%) 231 (Gatermann et al., 2007) and S. epidermidis (38-81\%) (Gill et al., 1983; Del' Alamo et al., 1999; 232 Gatermann et al., 2007). Teicoplanin nonsusceptible isolates occur in 3\% of S. epidermidis and in none of the S. hominis isolates (Del' Alamo et al., 1999). S. lugdunensis has nearly uniform in vitro susceptibility to most antimicrobials, including penicillins, cephalosporins and macrolides (Poutanen et al., 2001; Gatermann et al., 2007).

\section{Epidemiology}


Several studies show that most CNS infections are hospital-acquired or health-care related

(Rupp et al., 1994; Huebner et al., 1999). Colonization of patients and hospital staff with antibiotic

resistant S. epidermidis precedes infection with these organisms (Kloos et al., 1994; Nouwen et al., 1998; Widerström et al., 2006). Some clones are probably endemic in the hospital environment. CNS have the ability to survive in the intensive care unit (ICU) surroundings on medical devices and medical equipment for weeks to months (Neely et al., 2000). The clonal spread of identical or closely related methicillin-resistant CNS strains within hospitals and even between hospitals has been demonstrated (Monsen et al., 2000; Widerström et al., 2006). Frequent transmission of CNS between intubated patients was demonstrated in a multidisciplinary ICU (Agvald-Öhman et al., 2004). The spread of CNS strains is well studied in neonatal ICUs, where CNS are the major causative organism of sepsis. A relatively small number of molecular types of CNS can persist in the neonatal ICU for many years. The mecA gene carriage in these clusters is usually very high, which suggests that antibiotic resistance is one of the major selective forces (Krediet et al., 2004). Multi locus sequence typing identified a sequence type (ST 27), which contained exclusively ica-positive isolates and represented the majority of clinical strains within different hospitals in Germany. The ST 27 clone was also detected in a Norwegian hospital and in medical facilities in the United States (Kozitskaya et al., 2005). The combination of biofilm formation, antibiotic resistance and genetic flexibility (due to multiple copies of IS256) in the ST27 clone may explain why this clone is so predominant in hospital settings. It is tempting to assume that patients who are admitted to hospital are rapidly colonized with this clone and that this newly acquired microflora might represent the origin for later infection (Kozitskaya et al., 2005; Ziebuhr et al., 2006). Hospital personnel can also be responsible for spreading multi resistant CNS isolates (Hira et al., 2007). Clonal types can only be distinguished by genotypic methods and not by phenotypic appearance of the colonies or by antibiotype (Nouwen et al., 1998; Miragaia et al., 2002). Risk factors for the emergence and spread of CNS clones in 
antibiotic pressure in the environment, and hygienic standards (Widerström et al., 2006). The use of

265

266

267

contact and hand hygiene precautions is extremely important for preventing nosocomial colonization and infections. Maybe periodic surveillance of patients and staff in specific wards could be useful to avoid the spread of multi resistant CNS. A good antibiotic policy, in order to reduce the antibiotic pressure, will help to reduce the incidence of multi resistant CNS.

\section{Specific infections}

\subsection{Urinary tract infections (UTI)} S. saprophyticus is the second (after Escherichia coli) most frequent causative organism of uncomplicated urinary tract infections (UTI) in women. Complications, such as recurrent infection, acute pyelonephritis, nephrolithiasis, septicaemia and endocarditis have been documented but are rare (Raz et al., 2005; Widerström et al., 2007). The vast majority of infections occur in young, sexually active women. $S$. saprophyticus can also cause UTI in males of all ages (Raz et al., 2005). $S$. saprophyticus is found in 3-9\% of cases of uncomplicated acute cystitis (Christiaens et al., 1998; Grude et al., 2005; Nys et al., 2006). Frequency of isolation is age dependent. In a recent study, $S$. saprophyticus was isolated from $7 \%, 4 \%$ and $0.5 \%$ of subjects in age categories $11-20$ years, $21-50$ years and 51-70 years, respectively (Nys et al., 2006). S. saprophyticus can be pathogenic in low numbers $\left(<10^{5} \mathrm{cfu} / \mathrm{mL}\right)$ (Rupp et al., 1994). S. saprophyticus is probably often missed as causative organism of UTI, as the bacteriuria is considered to be nonsignificant, especially when bacterial counts are low.

S. saprophyticus has also been isolated from $7 \%$ of rectal swabs taken from carcasses of cattle and pigs. The micro-organism is a common contaminant of various food samples, especially of raw beef and pork (Raz et al., 2005). In humans, the major reservoir of S. saprophyticus is the gastrointestinal tract. The following risk factors have been identified: recent sexual intercourse, 
outdoor swimming and meat processing (Huebner et al., 1999). Colonization and infection is more

291 frequent during summer and fall.

Other CNS species, mainly S. epidermidis, are occasionally found as causative organisms in UTI ( $<5 \%$ of UTI in hospital environment). S. epidermidis is usually isolated from hospitalized, elderly patients with urinary catheters or other manipulations to the urinary tract (Rupp et al., 1994; Raz et al., 2005).

\subsection{Endocarditis}

The incidence and characteristics of CNS endocarditis were studied in a large cohort of patients from the International Collaboration on Endocarditis Merged Database (Chu et al., 2004).

CNS accounted for $7 \%$ of cases of definite native valve endocarditis (NVE), excluding endocarditis associated with injection drug use (Chu et al., 2004). Most CNS NVE is caused by S. epidermidis (85\%). The remainder is caused by S. hominis (6\%), S. lugdunesis (5\%), S. capitis, S. caprae and S. simulans. Rates of heart failure and mortality were found to be similar between patients with CNS and S. aureus NVE (Chu et al., 2004). Patients with NVE caused by staphylococci were significantly more likely to have health-care associated endocarditis than patients with viridans streptococcal NVE.

In a study from 1999, streptococci are responsible for $48 \%$ of cases of infective endocarditis, S. aureus for $23 \%$ and CNS for $6 \%$ (Hoen et al., 2002). These frequencies were also found in a study conducted between 1951 and 1965: S. epidermidis was the third most frequent isolated organism (in $10 \%$ of cases) in cases of bacterial endocarditis, after viridans streptococci $(47 \%)$ and $S$. aureus (24\%) (Dalton et al., 1967). Injecting heroin users are susceptible to right-sided endocarditis due to $S$. epidermidis (von Eiff et al., 2001).

Characteristics of patients with prosthetic valve endocarditis (PVE) were studied and compared with NVE patients in the International Collaboration on Endocarditis - Prospective Cohort 
316 Study (Wang et al., 2007). Patients with PVE had a higher rate of CNS infection (16.9\%) than 317 patients with NVE (8.3\%). In literature, higher rates (than in the study by Wang et al., 2007) of CNS 318 in infections of prosthetic valves are found (40-50\% of cases) (Huebner et al., 1999; von Eiff et al., 319 2001).

S. lugdunensis endocarditis has more features of $S$. aureus endocarditis than of CNS endocarditis. The infection is often aggressive, most cases are community-acquired and only a minority of patients (approximately 25\%) has prosthetic valves (Poutanen et al., 2001).

\subsection{Blood stream infections (BSI)}

Almost all cases of bacteremia due to CNS are nosocomial or at least health-care related in

origin. Intravascular and cardiovascular devices, such as peripheral and central catheters, vascular grafts, implanted defibrillators and coronary stents, are widely used. Catheter related infections are by far the most common cause of bacteremia due to CNS (Huebner et al., 1999).

330 Throughout the 1960s and 1970s, Gram-negative organisms were the most common pathogens 331 isolated from patients with nosocomial blood stream infections (BSI) (Wisplinghoff et al., 2004), but 332 in one study (Dalton et al., 1967), between 1951 an 1965, S. epidermidis accounted for 23\% of 333 positive blood cultures in patients with suspected bacteremia. Second and third most frequent 334 isolated organism was S. aureus (12\%) and Corynebacterium species (12\%). The high rates of 335 common skin bacteria (such as Corynebacterium species and S. epidermidis) in the study by Dalton 336 et al., 1967, raise concern about the clinical significance. The incidence of bacteremia caused by 337 CNS rose between $161 \%$ and $754 \%$, respectively in large teaching and small non-teaching hospitals, 338 between 1980 and 1989 (Rupp et al., 1994). During 1986 - 1989 CNS were the most frequently 339 reported cause of BSI, accounting for $27 \%$ of BSI (Schaberg et al., 1991). 
342 to CNS was $25.7 \%$ in an intensive care unit (ICU) and $13.8 \%$ in a non-ICU ward. In Flanders, 343 Belgium, CNS account for $25.9 \%$ of all nosocomial BSI. Forty-eight percent of BSI cases in 344 Flanders were due to catheter related sepsis, $32 \%$ to sepsis of unknown origin, and $20 \%$ were 345 associated with another infection or an invasive manipulation (Suetens et al., 2002). CNS are the most common pathogens in catheter-related infections (50-70\% of cases). In 347 addition to bacteremia, CNS, mainly S. epidermidis, can cause exit-site infections, tunnel infections, 348 infected thrombophlebitis, endocarditis and abscesses (Rupp et al., 1994; Huebner et al., 1999). At 349 the time of removal, 8-40\% of all catheters are colonized by CNS (Rupp et al., 1994).

350 Positive blood cultures with CNS can be explained by contamination, true bacteremia or transient 351 benign bacteremia (Rupp et al., 1994). It may be very difficult to distinguish between infection and 352 contamination. As the positive predictive value of a blood culture growing CNS varies from 6 to 353 12\% (Correa et al., 1999), the criteria used for defining true bacteremia influence reported CNS 354 prevalence. The CDC criteria for defining bloodstream infection (Garner et al., 1988) are used in 355 most of the studies. The intensity of surveillance also influences the reported BSI incidence and 356 prevalence of CNS.

There is increasing evidence that the mucosa, rather than skin, is the likely source of CNS bacteremia in cancer patients (Costa et al., 2004; Costa et al., 2006). A recent study showed that among cancer patients with CNS positive blood cultures and an indwelling central venous catheter

360 (CVC), the mucosal sites were the most frequently colonised by CNS (nasal mucosa in $86 \%$, rectal 361 mucosa in $40 \%$ ). The skin at the CVC site was colonised by CNS in $32 \%$ of patients. Among patients 362 with true bacteremia, 6 mucosal isolates and only 1 skin isolate were genetically related to the isolate 363 recovered from blood based on pulsed-field gel electrophoresis (Costa et al., 2006). A review of the 364 literature confirms that CNS colonise mucosal sites including gut, nares and throat and may 365 translocate from mucosal sites to the bloodstream (Costa et al., 2004). This is supported by 366 epidemiological, experimental, clinical and molecular relatedness studies. The assumption that the skin is the primary source of CNS infection has been the reason to try to achieve a reduction of CNS 
catheter related bacteremia with skin decontamination and the use of maximum barrier precautions at

369 the time of CVC insertion. However, not all studies show a positive effect of these two interventions

370 (Costa et al., 2004).

\subsection{Foreign body-related infections (FBRIs)}

Insertion or implantation of medical devices is associated with a risk of bacterial and fungal

infections. Medical devices are increasingly used in almost all fields of medicine for diagnostic

and/or therapeutic procedures. The contamination of the device occurs most likely by inoculation

with only a few micro-organisms from the patient's skin or mucous membranes during implantation or subsequent manipulations (Rupp et al., 1994; von Eiff et al., 2001; von Eiff et al., 2005). The pathogens may also be acquired from the hands of the surgical or clinical staff (von Eiff et al., 2005). Staphylococci, particularly S. epidermidis, account for the majority of FBRIs (von Eiff et al., 2005).

Most CNS isolates causing foreign body-related infections (FBRI) are methicillin resistant.

Neurosurgical devices (ventricular shunts, implantable stimulators, intracranial pressure devices) are frequently used. Of the pathogens isolated from ventriculoperitoneal shunt infections in pediatric patients less than 8 years old, 53\% were CNS (Filka et al., 1999). Clinical symptoms can be subtle and nonspecific. (Huebner et al., 1999). In a review of CSF shunt infections, caused by a single pathogen, CNS and $S$. aureus were isolated with equal frequency, i. e. in $23 \%$ of cases each (Wang et al., 2004). Others reported that CNS are the most common cause of shunt infections (40$60 \%$ of infections) (Rupp et al., 1994). In a retrospective study, pure culture of CNS accounted for $11 \%$ of cases of adult bacterial meningitis (Huang et al., 2005). All cases had post-neurosurgical states as underlying condition.

CNS cause $17-56 \%$ of episodes of continuous ambulatory peritoneal dialysis-associated 392 peritonitis (Rupp et al., 1994, Monsen et al., 2000). S. epidermidis is the predominant species (78\%) 393 followed by S. haemolyticus (11\%) (Monsen et al., 2000). From 1991 to 1998, the incidence of 
394 dialysis-related peritionitis caused by S. epidermidis decreased, probably due to the introduction of a 395 new dialysis system. Even so, S. epidermidis was still the most common cause of peritonitis in 1998, 396 causing $28 \%$ of culture positive cases (Zelenitsky et al., 2000).

Up to $60 \%$ of vascular graft infections and $20-40 \%$ of prosthetic joint infections are caused 398 by CNS (Rupp et al., 1994). other joint prostheses, or fibrous capsular contracture syndrome after mammary augmentation with silicone prostheses (von Eiff et al., 2001).

\subsection{Surgical site infection}

404

S. aureus is the most common pathogen isolated from surgical site infections (SSI) (20\%),

followed by CNS (14\%) and Enterococcus species (12\%) (CDC, 1996). In a secondary care hospital, 407 CNS were the third (10\%) most frequently isolated micro-organism, after S. aureus (21\%) and 408 Streptococcus species (11.2\%) (Cantlon et al., 2006). Outbreaks of SSI originating from operating 409 room personnel have been reported, but probably most infections are indogenous (Huebner et al., 410 1999). Sternal osteomyelitis following median sternotomy is caused predominantly by CNS (Rupp et 411 al., 1994).

CNS are by far the most common pathogens isolated from vitreous biopsies in cases of endophthalmitis. In a review of 67 cases of endophthalmitis, $31 \%$ of the culture positive biopsies 417 (only 44\%) yielded CNS as pathogen (Karacal et al., 2007). Most cases of endophthalmitis were 418 postoperative $(73.5 \%)$, mainly after cataract surgery. Other cases were associated with endogenous origin $(13 \%)$, post-intravitreal injection $(6 \%)$, keratitis $(4 \%)$ and post-traumatic $(3 \%)$. Post-traumatic 
420

421

422

423

424

425

426

427

endophthalmitis, a complication of a penetrating eye injury, is caused by CNS in $28 \%$ of cases (Abu

El-Asrar et al., 1999).

\subsection{Mastitis}

CNS are rarely associated with mastitis in humans. In lactation mastitis, the agents most frequently cultured from milk are S. aureus and CNS (Barbosa-Cesnik et al., 2003). In non lactational breast abscesses, CNS are rarely isolated as sole pathogen. Some cases of non lactational breast abscesses, especially with $S$. lugdunensis have been published in literature (Asnis et al., 2003). S. aureus and anaerobes are the most common organisms to cause breast abscesses (Surani et al., 1993).

\section{Conclusions and Outlook}

CNS are a group of micro-organisms that are increasingly implicated as a cause of significant infection. The infection rate has been correlated with the increase in the use of invasive and indwelling medical devices and the growing number of immunocompromised patients. Community acquired, primary CNS infections are rare, except for S. saprophyticus UTI, NVE and S. lugdunensis infections. The increase of CNS infections is particularly high in bacteraemia. CNS are now a major cause of nosocomial or health care related infections. The consequences of these infections are substantial, both in morbidity and mortality and in financial costs. Clonal spread of CNS clusters within and even between hospitals has been demonstrated. This is of major concern as CNS are often multi-drug resistant and can serve as a reservoir of resistance genes. Implementation of infection control measures similar to those used for MRSA may be necessary to prevent further spread of methicillin and multi-drug resistant CNS. 


\section{Conflict of Interest}

None of the authors (A. Piette, G. Verschraegen) has a financial or personal relationship with other people or organizations that could inappropriately influence or bias the paper entitled "Role of coagulase-negative staphylococci in human disease".

\section{References}

Abu el-Asrar, A.M., al-Amro, S.A., al-Mosallam, A.A., al-Obeidan, S., 1999. Post-traumatic endophthalmitis: causative organisms and visual outcome. Eur. J. Ophthalmol. 9, 21-31.

Agvald-Ohman, C., Lund, B., Edlund, C., 2004. Multiresistant coagulase-negative staphylococci disseminate frequently between intubated patients in a multidisciplinary intensive care unit. Crit. Care. 8, R42-R47.

Asnis, D.S., St John, S., Tickoo, R., Arora, A., 2003. Staphylococcus lugdunensis breast abscess: is it real? Clin. Infect. Dis. 36, 1348.

Bannerman, T., 2003. Staphylococcus, Micrococcus and other catalase-positive cocci that grow aerobically. In Murray, P., Baron, E., Jorgerson, J., Pfaller, M., Yolken, R., (Eds.) Manual of clinical microbiology, ASM Press, Washington.

Barbosa-Cesnik, C., Schwartz, K., Foxman, B., 2003. Lactation mastitis. JAMA. 289, 16091612.

Biavasco, F., Vignaroli, C., Varaldo, P.E., 2000. Glycopeptide resistance in coagulasenegative staphylococci. Eur. J. Clin. Microbiol. Infect. Dis. 19, 403-417.

Biedenbach, D.J., Bell, J.M., Sader, H.S., Fritsche, T.R., Jones, R.N., Turnidge, J.D., 2007. Antimicrobial susceptibility of Gram-positive bacterial isolates from the Asia-Pacific region and an in vitro evaluation of the bactericidal activity of daptomycin, vancomycin, and teicoplanin: a SENTRY Program Report (2003-2004). Int. J. Antimicrob. Agents. 30, 143-149. 
473 Significant pathogens isolated from surgical site infections at a community hospital in the Midwest. 474 Am. J. Infect. Control. 34, 526-529.

CDC, 1996. National nosocomial infections surveillance (NNIS) report, data summary from october 1986 - april 1996, issued may 1996. Am. J. Infect. Control. 24, 380-388.

resistant staphylococci with special reference to Staphylococcus haemolyticus. Indian J. Med.

Microbiol. 25, 50-52.

Christiaens, T.H., Heytens, S., Verschraegen, G., De Meyere, M., De Maeseneer, J., 1998.

Which bacteria are found in Belgian women with uncomplicated urinary tract infections in primary health care, and what is their susceptibility pattern anno 95-96. Acta Clin. Belg. 53, 184-188.

Stryjewski, M.E., Pappas, P., Anstrom, K.J., Eykyn, S., Habib, G., Benito, N., Fowler, V.G Jr, 2004.

Native valve endocarditis due to coagulase-negative staphylococci: report of 99 episodes from the

Corse, J., Williams, R.E., 1968. Antibiotic resistance of coagulase-negative staphylococci and micrococci. J. Clin. Pathol. 21, 722-728.

Costa, S.F., Miceli, M.H., Anaissie, E.J., 2004. Mucosa or skin as source of coagulasenegative staphylococcal bacteraemia? Lancet Infect. Dis. 4, 278-286.

Costa, S.F., Barone, A.A., Miceli, M.H., van der Heijden, I.M., Soares, R.E., Levin, A.S., Costerton, J.W., Stewart, P.S., Greenberg, E.P., 1999. Bacterial biofilms: a common cause of 
Cuevas, O., Cercenado, E., Vindel, A., Guinea, J., Sanchez-Conde, M., Sanchez-Somolinos,

499

500

501

502

503

504

505

506

507

508

509

510

511

512

513

514

515

516

517

518

M., Bouza, E., 2004. Evolution of the antimicrobial resistance of Staphylococcus spp. in Spain: Five nationwide prevalence studies, 1986 to 2002. Antimicrob. Agents Chemother. 48, 4240-4245.

Dalton, H.P., Allison, M.J., 1967. Etiology of bacteremia. Appl. Microbiol. 15, 808-814.

Del’ Alamo, L., Cereda, R.F., Tosin, I., Miranda, E.A., Sader, H.S., 1999. Antimicrobial susceptibility of coagulase-negative staphylococci and characterization of isolates with reduced susceptibility to glycopeptides. Diagn. Microbiol. Infect. Dis. 34, 185-191.

de Mattos, E.M., Teixeira, L.A., Alves, V.M., Rezenda e Resende, C.A., da Silva Coimbra, M.V., da Silva-Carvalho, M.C., Ferreira-Carvalho, B.T., Figueiredo, A.M, 2003. Isolation of methicillin-resistant coagulase-negative staphylococci from patients undergoing continuous ambulatory peritoneal dialysis (CAPD) and comparison of different molecular techniques for discriminating isolates of Staphylococcus epidermidis. Diagn. Microbiol. Infect. Dis. 45, 13-22.

Euzéby, J.P., 2007, LSPN List of prokaryotic names with standing in nomenclature, http://www.bacterio.cict.fr/

Filka, J., Huttova, M., Tuharsky, J., Sagat, T., Kralinsky, K., Kremery V., 1999. Nosocomial meningitis in children after ventriculoperitoneal shunt insertion. Acta Paediatr. 88, 576-578.

Frebourg, N.B., Lefebvre, S., Baert, S., Lemeland, J.F., 2000. PCR-based assay for discrimination between invasive and contaminating Staphylococcus epidermidis strains. J. Clin. Microbiol. 38, 877-880.

Garner, J.S., Jarvis, W.R., Emory, T.G., Horan, T.C., Hughes, J.M., 1988. CDC definitions for nosocomial infections. Am. J. Infect. Control. 16, 128-140.

Garrison, M.W., Neumiller, J.J., Setter, S.M., 2005. Tigecycline: an investigational glycylcycline antimicrobial with activity against resistant gram-positive organisms. Clin. Ther. 27, $12-22$.

Gatermann, S.G., Koschinski, T., Friedrich, S., 2007. Distribution and expression of macrolide resistance genes in coagulase-negative staphylococci. Clin. Microbiol. Infect. 13, 777-781. 
Gill, V.J., Selepak, S.T., Williams, E.C., 1983. Species identification and antibiotic

525

susceptibilities of coagulase-negative staphylococci isolated from clinical specimens. J. Clin. Microbiol. 18, 1314-1319.

Grude, N., Tveten, Y., Jenkins, A., Kristansen, B.E., 2005. Uncomplicated urinary tract infections. Scand. J. Prim. Health care. 23, 115-119.

Hanssen, A.M., Kjeldsen, G., Sollid, J.U., 2004. Local variants of Staphylococcal cassette chromosome mec in sporadic methicillin-resistant Staphylococcus aureus and methicillin-resistant coagulase-negative Staphylococci: evidence of horizontal gene transfer? Antimicrob. Agents Chemother. 48, 285-296.

Harraghy, N., Kerdudou, S., Herrmann, M., 2007. Quorum-sensing systems in staphylococci as therapeutic targets. Anal. Bioanal. Chem. 387, 437-444.

Heikens, E., Fleer, A., Paauw, A., Florijn, A.C., Fluit, A., 2005. Comparison of genotypic and phenotypic methods for species-level identification of clinical isolates of coagulase-negative staphylococci. J. Clin. Microbiol. 43, 2286-2290.

Higuchi, W., Isobe, H., Iwao, Y., Dohmae, S., Saito, K., Takano, T., Otsuka, T., Baranovich, T., Endo, C., Suzuki, N., Tomiyama, Y., Yamamoto, T., 2007. Extensive multidrug resistance of coagulase-negative staphylococci in medical students. J. Infect. Chemother. 13, 63-66.

Hira, V., Sluijter, M., Estevão, S., Horst-Kreft, D., Ott, A., de Groot, R., Hermans, P.W., Kornelisse, R.F., 2007. Clinical and molecular epidemiologic characteristics of coagulase-negative staphylococcal bloodstream infections in intensive care neonates. Pediatr. Infect. Dis. J. 26, 607-612. Hoen B., Alla, F., Selton-Suty, C., Béguinot, I., Bouvet, A., Briançon, S., Casalta, J.P., Danchin, N., Delahaye, F., Etienne, J., Le Moing, V., Leport, C., Mainardi, J.L., Ruimy, R., Vandenesch, F., 2002. Changing profile of infective endocarditis, results of a 1-year survey in France. JAMA. 288, 75-81. 
549 Coagulase-negative staphylococcal meningitis in adults: clinical characteristics and therapeutic 550 outcomes. Infection. 33, 56-60.

Huebner, J., Goldmann, D.A., 1999. Coagulase-negative staphylococci: Role as Pathogens.

552 Annu. Rev. Med. 50, 223-236.

Jarløv, J.O., Højbjerg, T., Busch-Sørensen, C., Scheibel, J., Møller, J.K., Kolmos, H.J., Wandall, D.A., 1996. Coagulase-negative Staphylococci in Danish blood cultures: species distribution and antibiotic susceptibility. J. Hosp. Infect. 32, 217-227.

Jones, R.N., Fritsche, T.R., Sader, H.S., Ross, J.E., 2007. LEADER surveillance program results for 2006: an activity and spectrum analysis of linezolid using clinical isolates from the United States (50 medical centers). Diagn. Microbiol. Infect. Dis. 59, 309-317.

Jones, R.N., Fritsche, T.R., Sader, H.S., Ross, J.E., 2007. Zyvox® annual appraisal of potency and spectrum program results for 2006: an activity and spectrum analysis of linezolid using clinical isolates from 16 countries. Diagn. Microbiol. Infect. Dis. 59, 199-209.

Karacal, H., Kymes, S.M., Apte, R.S., 2007. Retrospective analysis of etiopathogenesis of all cases of endophthalmitis at a large tertiary referral center. Int. Ophthalmol. 27, 251-259.

Kawamura, Y., Hou, X.G., Sultana, F., Hirose, K., Miyake, M., Shu, S.E., Ezaki, T., 1998.

Distribution of Staphylococcus species among human clinical specimens and emended description of Staphylococcus caprae. J. Clin. Microbiol. 36, 2038-2042.

Kleeman, K.T., Bannerman, T.L., Kloos, W.E., 1993. Species distribution of coagulasenegative staphylococcal isolates at a community hospital and implications for selection of staphylococcal identification procedures. J. Clin. Microbiol. 31, 1318-1321.

Kloos, W.E., Schleifer, K.J., 1975. Simplified scheme for routine identification of human Staphylococcus species. J. Clin. Microbiol. 1, 82-88.

Kloos, W.E., Bannerman, T.L., 1994. Update on clinical significance of coagulase-negative staphylococci. Clin. Microbiol. Rev. 7, 117-140. 
Koksal, F., Yasar, H., Samasti, M., 2007. Antibiotic resistance patterns of coagulase-negative

575

576

staphylococcus strains isolated from blood cultures of septicemic patients in Turkey. Microbiol. Res. DOI:10.1016/j.micres.2007.03.004.

Kong, K.F., Vuong, C., Otto, M., 2006. Staphylococcus quorum sensing in biofilm formation and infection. Int. J. Med. Microbiol. 296, 133-139.

Koziol-Montewka, M., Szczepanik, A., Baranowicz, I., Jozwiak, L., Ksiazek, A., Kaczor, D., 2006. The investigation of Staphylococcus aureus and coagulase-negative staphylococci nasal carriage among patients undergoing haemodialysis. Microbiol. Res. 161, 281-287.

Kozitskaya, S., Olson, M.E., Fey, P.D., Witte, W., Ohlsen, K., Ziebuhr, W., 2005. Clonal analysis of Staphylococcus epidermidis isolates carrying or lacking biofilm-mediating genes by multilocus sequence typing. J. Clin. Microbiol. 43, 4751-4757.

Krediet, T.G., Mascini, E.M., van Rooij, E., Vlooswijk, J., Paauw, A., Gerards, L.J., Fleer, A., 2004. Molecular epidemiology of coagulase-negative staphylococci causing sepsis in a neonatal intensive care unit over an 11-year period. J. Clin. Microbiol. 42, 992-995.

Layer, F., Ghebremedhin, B., Moder, K., König, W., König, B., 2006. Comparative study using various methods for identification of Staphylococcus species in clinical specimens. J. Clin. Microbiol. 44, 2824-2830.

Mack, D. Davies, A.P., Harris, L.G., Rohde, H., Horstkotte, M.A., Knobloch, J.K., 2007. Microbial interactions in Staphylococcus epidermidis biofilms. Anal. Bioanal. Chem. 387, 399-408.

Mellmann, A., Becker, K., von Eiff, C., Keckevoet, U., Schumann, P., Harmsen, D., 2006. Sequencing and staphylococci identification. Emerg. Infect. Dis. 12, 333-336.

Miragaia, M., Couto, I., Pereira, S.F., Kristinsson, K.G., Westh, H., Jarløv, J.O., Carriço, J., Almeida, J., Santos-Sanches, I., de Lencastre, H., 2002. Molecular characterization of methicillinresistant Staphylococcus epidermidis clones: evidence of geographic dissemination. J. Clin. Microbiol. 40, 430-438. 
600

601

602

603

604

605

606

607

608

609

610

among patients with peritonitis associated with continuous ambulatory peritoneal dialysis. Kidney Int. 57, 613-618.

Neely, A.N., Maley, M.P., 2000. Survival of Enterococci and Staphylococci on hospital fabrics and plastic. J. Clin. Microbiol. 38, 724-726.

Nouwen, J.L., van Belkum, A., de Marie, S., Sluijs, J., Wielenga, J.J., Kluytmans, J.A., Verbrugh, H.A., 1998. Clonal expansion of Staphylococcus epidermidis strains causing Hickman catheter-related infections in a hemato-oncologic department. J. Clin. Microbiol. 36, 2696-2702.

Nunes, A.P., Teixeira, L.M., Iorio, N.L., Bastos, C.C., de Sousa Fonseca, L., Souto-Padrón, T., dos Santos, K.R., 2006. Heterogeneous resistance to vancomycin in Staphylococcus epidermidis, Staphylococcus haemolyticus and Staphylococcus warneri clinical strains: characterisation of glycopeptide susceptibility profiles and cell wall thickening. Int. J. Antimicrob. Agents. 27, 307-315.

Nys, S., van Merode, T., Bartelds, A.I., Stobberingh, E.E., 2006. Urinary tract infections in general practice patients: diagnostic tests versus bacteriological culture. J. Antimicrob. Chemother. $57,955-958$.

Potoski, B.A., Adams, J., Clarke, L., Shutt, K., Linden, P.K., Baxter, C., Pasculle, A.W., Capitano, B., Peleg, A.Y., Szabo, D., Paterson, D.L., 2006. Epidemiological profile of linezolidresistant coagulase-negative staphylococci. Clin. Infect. Dis. 43, 165-171.

Poutanen, S.M., Baron, E.J., 2001. Staphylococcus lugdunensis: a notably distinct coagulasenegative staphylococcus. Clin. Microbiol. Newsletter. 23,147-150.

Qin, Z., Yang, X., Yang, L., Jiang, J., Ou, Y., Molin, S., Qu, D., 2007. Formation and properties of in vitro biofilms of ica-negative Staphylococcus epidermidis clinical isolates. J. Med. Microbiol. 56, 83-93.

Raz, R., Colodner, R., Kunin, C.M., 2005. Who Are You—Staphylococcus saprophyticus? Clin. Infect. Dis. 40, 896-898. 
625

Antimicrobial susceptibility of the pathogens of bacteraemia in the UK and Ireland 2001-2002: the BSAC bacteraemia resistance surveillance programme. J. Antimicrob. Chemother. 53, 1018-1032. Rohde, H., Kalitzky, M., Kröger, N., Scherpe, S., Horstkotte, M.A., Knobloch, J.K., Zander, A.R., Mack, D., 2004. Detection of virulence-associated genes not useful for discriminating between invasive and commensal Staphylococcus epidermidis strains from a bone marrow transplant unit. J. Clin. Microbiol. 42, 5614-5619.

Rupp, M.E., Archer, G.L., 1994. Coagulase-negative staphylococci: pathogens associated with medical progress. Clin. Infect. Dis. 19, 231-245.

Sader, H.S., Watters, A.A., Fritsche, T.R., Jones, R.N., 2007. Daptomycin antimicrobial activity tested against methicillin-resistant staphylococci and vancomycin-resistant enterococci isolated in European medical centers (2005). BMC Infect. Dis. 7, 29 DOI:10.1186/1471-2334-7-29.

Schaberg, D.R., Culver, D.H., Gaynes, R.P., 1991. Major trends in the microbial etiology of nosocomial infection. Am. J. Med. 91 ,S72-S75.

Singhal, R., Dhawan, S., Mohanty, S., Sood, S., Dhawan, B., Das, B., Kapil, A., 2006. Species distribution and antimicrobial susceptibility of coagulase negative staphylococci in a tertiary care hospital. Indian J. Med. Res. 123, 569-470.

Sivadon, V., Rottman, M., Chaverot, S., Quincampoix, J.C., Avettand, V., de Mazancourt, P., Bernard, L., Trieu-Cuot, P., Féron, J.M., Lortat-Jacob, A., Piriou, P., Judet, T., Gaillard, J.L., 2005. Use of genotypic identification by $\operatorname{sod} A$ sequencing in a prospective study to examine the distribution of coagulase-negative Staphylococcus species among strains recovered during septic orthopedic surgery and evaluate their significance. J. Clin. Microbiol. 43, 2952-2954.

Suetens, C., Leens, E., Versporten, A., Jans, B., 2002. Hogere incidentie septicemieën met coagulase-negatieve stafylokokken na introductie kwaliteitsdecreet in Vlaanderen. Noso-info. 1, 1113. 
Surani, S., Chandna, H., Weinstein, R.A., 1994. Breast abscess: coagulase-negative

650

651

652

653

654

655

656

657

658

659

660

661

662

663

664

665

666

667

668

669

670

671

672

673

staphylococcus as a sole pathogen. Clin. Infect. Dis. 19, 814-815.

Vandecasteele, S.J., Peetermans, W.E., Merckx, R., Rijnders B.J., Van Eldere, J., 2003.

Reliability of the $i c a$, aap and atlE genes in the discrimination between invasive, colonizing and contaminant Staphylococcus epidermidis isolates in the diagnosis of catheter-related infections. Clin.

Microbiol. Infect. 9, 114-119.

von Eiff C., Proctor, R.A., Peters, G., 2001. Coagulase-negative staphylococci: pathogens have major role in nosocomial infections. Postgrad. Med. 110, 63-76.

von Eiff, C., Peters, G., Heilmann, C., 2002. Pathogenesis of infections due to coagulase negative staphylococci. Lancet Infect. Dis. 2, 677-85.

von Eiff, C., Jansen, B., Kohnene, W., Becker, K., 2005. Infections associated with medical devices, pathogenesis, management and prophylaxis. Drugs. 65, 179-214.

Vuong, C., Otto, M., 2002. Staphylococcus epidermidis infections. Microbes Infect. 4, 481489.

Wang, K.W., Chang, W.N., Shih, T.Y., Huang, C.R., Tsai, N.W., Chang, C.S., Chuang, Y.C., Liliang, P.C., Su, T.M., Rau, C.S., Tsai, Y.D., Cheng, B.C., Hung, P.L., Chang, C.J., Lu, C.H., 2004. Infection of cerebrospinal fluid shunts: causative pathogens, clinical features and outcomes. Jpn. J. Infect. Dis. 57, 44-48.

Wang, A., Athan, E., Pappas, P.A., Fowler, V.G., Olaison, L., Paré, C., Almirante, B., Muñoz, P., Rizzi, M., Naber, C., Logar, M., Tattevin, P., Iarussi, D.L., Selton-Suty, C., Jones, S.B., Casabé, J., Morris, A., Corey, G.R., Cabell, C.H., 2007. Contemporary clinical profile and outcome of prosthetic valve endocarditis. JAMA. 12, 1354-1361.

Widerström, M., Monsen, T., Karlsson C., Wiström, J., 2006. Molecular epidemiology of methicillin-resistant coagulase-negative staphylococci in a Swedish county hospital: evidence of intra and interhospital clonal spread. J. Hosp. Infect. 64, 177-183. 
675 epidemiology of Staphylococcus saprophyticus isolated from women with uncomplicated 676 community-acquired urinary tract infection. J. Clin. Microbiol. 45, 1561-1564.

677 Wisplinghoff, H., Bischoff, T., Tallent, S.M., Seifert, H., Wenzel, R.P., Edmond, M.B., 2004. 678 Nosocomial bloodstream infections in US hospitals: analysis of 24,179 cases from a prospective 679 nationwide surveillance study. Clin. Infect. Dis. 39, 309-17.

680 Xu, L., Li, H., Vuong, C., Vadyvaloo, V., Wang, J., Yao, Y., Otto, M., Gao, Q., 2006. Role 681 of the luxS quorum-sensing system in biofilm formation and virulence of Staphylococcus 682 epidermidis. Infect. Immun. 74, 488-496.

683 Zelenitsky, S., Barns, L., Findlay, I., Alfa, M., Ariano, R., Fine, A., Harding, G., 2000. 684 Analysis of microbiological trends in peritoneal dialysis-related peritonitis from 1991 to 1998. Am. 685 J. Kidney Dis. 36, 1009-1013.

686 Ziebuhr, W., Hennig, S., Eckart, M., Kränzler, H., Batzilla, C., Kozitskaya, S., 2006. 687 Nosocomial infections by Staphylococcus epidermidis: how a commensal bacterium turns into a 688 pathogen. Int. J. Antimicrob. Agents. 28S, S14-S20. 
690 Species distribution (\%), sample origin, used identification method of CNS in clinical samples in different studies (country and publication date in 691 heading).

\begin{tabular}{|c|c|c|c|c|c|c|c|c|c|c|c|}
\hline & $\begin{array}{l}\text { USA } \\
1983 \text { (1) }\end{array}$ & $\begin{array}{l}\text { USA } \\
1993 \text { (2) }\end{array}$ & $\begin{array}{l}\text { Denmark } \\
1996(3)\end{array}$ & $\begin{array}{l}\text { Japan } \\
1998(4)\end{array}$ & $\begin{array}{l}\text { Brazil } \\
1999(5)\end{array}$ & $\begin{array}{l}\text { Spain } \\
2004(6)\end{array}$ & $\begin{array}{c}\text { France } \\
2005(7)\end{array}$ & $\begin{array}{c}\text { India } \\
2006(8)\end{array}$ & $\begin{array}{l}\text { India } \\
2007(9)\end{array}$ & $\begin{array}{l}\text { Germany } \\
2007(10)\end{array}$ & $\begin{array}{l}\text { Turkey } \\
2007 \text { (11) }\end{array}$ \\
\hline S. epidermidis & 75 & 65 & 58 & 50 & 50 & 56 & 71 & 34 & 13 & 67 & 44 \\
\hline S. haemolyticus & 7 & 13 & 9 & 16 & 10 & 5 & 2 & 13 & 72 & 12 & 12 \\
\hline S. hominis & 5 & 7 & 12 & 5 & 12 & 18 & 4 & 2 & 6 & 9 & 9 \\
\hline S. simulans & 1 & 2 & & 6 & & 1 & 1 & & 2 & 1 & 2 \\
\hline S. capitis & 2 & 4 & $<1$ & 5 & & 3 & 6 & 10 & 1 & 1 & 8 \\
\hline S. saprophyticus & 1 & 1 & 1 & 5 & & 5 & & & & $<1$ & 3 \\
\hline S. warneri & 3 & 4 & 2 & 3 & & 4 & 7 & 1 & 1 & 2 & 4 \\
\hline S. lugdunensis & & 3 & $<1$ & 2 & & & 3 & 13 & 1 & 3 & 9 \\
\hline S. caprae & & & & 14 & & & 2 & & & 1 & \\
\hline S. cohnii & $<1$ & 1 & 1 & $<1$ & 6 & 0 & $<1$ & & & 1 & $<1$ \\
\hline S. auricularis & & $<1$ & & $<1$ & & & & & & & $<1$ \\
\hline S. schleiferi & & & & & & & & 12 & & 1 & $<1$ \\
\hline S. xylosis & & & & & & 0 & & 6 & & 1 & 5 \\
\hline S. pasteuri & & & & & & & 2 & & & & \\
\hline sample origin & CS & $\mathrm{CS}$ & BSI & $\mathrm{CS}$ & BSI & & BJI & $\mathrm{CS}$ & $\mathrm{CS}$ & BSI & BSI \\
\hline identification & SP & Vitek1 & SP & DNA & Microsc & SP & $\operatorname{sod} A$ & SP & Vitek2 & $\mathrm{SP}+\operatorname{sod} A$ & API \\
\hline
\end{tabular}

692 (1) Gill et al. (2) Kleeman et al. (3) Jarløv et al. (4) Kawamura et al. (5) Del' Alamo et al. (6) Cuevas et al. (7) Sivadon et al. (8) Singhal et al. (9)

693 Chaudhury et al. (10) Gatermann et al. (11) Koksal et al.; CS: clinical specimens, BJI: bone and joint infections; SP: standard procedures (based on

694 Kloos and Schleifer), Vitek1: Vitek GP card (Biomérieux), sodA: sodA sequencing, DNA: DNA-DNA hybridization, Microsc: Microscan positive 695 combo panel type 6 (DADE MicroScan Inc., Sacramento, CA), Vitek2: Vitek ID 32 Staph (Biomérieux), API: API ID 32 Staph (Biomérieux) 
697 Percentage susceptibility of CNS in different studies (in heading country and publication date); MR: \% susceptibility in methicillin resistant strains, MS:

$698 \%$ susceptibility in methicillin susceptible strains

\begin{tabular}{|c|c|c|c|c|c|c|c|c|c|c|c|}
\hline \multirow{3}{*}{$\begin{array}{l}\% \text { susceptibility } \\
\text { methicillin/oxacillin }\end{array}$} & \multirow{3}{*}{$\begin{array}{c}\text { Spain } \\
2002(1) \\
39\end{array}$} & \multicolumn{2}{|c|}{$\begin{array}{l}\text { UK, Ireland } \\
2004 \text { (2) }\end{array}$} & \multicolumn{2}{|c|}{$\begin{array}{l}\text { Asia_Pacific } \\
\text { region } 2007(3)\end{array}$} & \multirow{3}{*}{$\begin{array}{c}\text { USA } \\
2007(4) \\
23,1\end{array}$} & \multirow{3}{*}{$\begin{array}{c}\text { Europe, Asia, } \\
\text { Australia, Latin } \\
\text { America 2007 (5) } \\
25,7\end{array}$} & \multicolumn{2}{|c|}{$\begin{array}{c}\text { Turkey } \\
2007 \text { (6) }\end{array}$} & \multicolumn{2}{|c|}{$\begin{array}{l}\text { Europe, Turkey, } \\
\text { Israel } 2007 \text { (7) }\end{array}$} \\
\hline & & \multicolumn{2}{|c|}{24} & \multicolumn{2}{|c|}{15,2} & & & \multicolumn{2}{|c|}{32,5} & \multicolumn{2}{|c|}{28} \\
\hline & & MR & MS & MR & MS & & & MR & MS & MR & MS \\
\hline penicillin & 21 & 0 & 24.5 & & & 12.1 & 15.3 & 0 & 9 & & \\
\hline ceftriaxone & & & & & & 51.1 & 47.6 & & & & \\
\hline ciprofloxacin & 55 & 40.8 & 81.6 & & & 42.2 & 46.5 & 33 & 77 & 27.8 & 86.9 \\
\hline levofloxacin & & & & 50.2 & 89.1 & 42.3 & 47.5 & & & 28.1 & 87.3 \\
\hline cotrimoxazole & 76 & & & 60.8 & 89.1 & 61.9 & 59.3 & 32 & 62 & 52.6 & 91.8 \\
\hline gentamicin & 72 & 25.7 & 78.6 & & & 71.3 & 57.7 & 10 & 83 & & \\
\hline tetracycline & & 39.2 & 67.3 & 83.5 & 89.1 & 86.9 & 83.7 & 40 & 55 & & \\
\hline erythromycin & 37 & 27.3 & 62.2 & 31.8 & 78.3 & 28.8 & 33.8 & 20 & 63 & 27.2 & 65.7 \\
\hline clindamycin & 66 & 69.1 & 93.9 & 68.6 & 95.7 & 59.9 & 60.7 & 28 & 82 & 67 & 94.8 \\
\hline chloramphenicol & 91 & & & 87.1 & 91.3 & & & 44 & 87 & 86.6 & 97.4 \\
\hline fusidic acid & & & & & & & & 75 & 85 & & \\
\hline rifampicin & 93 & & & & & & & & & 85.3 & 96.1 \\
\hline teicoplanin & 100 & 65 & 77.6 & 96.1 & 89.1 & 99.3 & 99.3 & 100 & 100 & 97.3 & 99.6 \\
\hline vancomycin & 100 & 99.7 & 100 & 100 & 100 & 100 & 100 & 100 & 100 & 100 & 100 \\
\hline linezolid & 100 & 100 & 100 & 100 & 100 & 98.4 & 99.5 & & & 100 & 100 \\
\hline quinupristin/dalfopristin & 100 & & & 99.6 & 100 & 99.3 & 99 & & & 99.3 & 100 \\
\hline daptomycin & & & & & & 100 & & & & 100 & 99.6 \\
\hline
\end{tabular}

699 (1) Cuevas et al. (2) Reynolds et al. (3) Biedenbach et al. (4) Jones et al., 2007a (5) Jones et al., 2007b (6) Koksal et al. (7) Sader et al. 